\title{
Q1 Residual stress analysis in laser welded NiTi sheets using synchrotron X-ray diffraction
}

\author{
Q2 J.P. Oliveira ${ }^{\text {a,* }}$, F.M. Braz Fernandes ${ }^{\text {a }}$, R.M. Miranda ${ }^{\text {b }}$, N. Schell ${ }^{\text {c }}$,.L. Ocaña ${ }^{\mathrm{d}}$

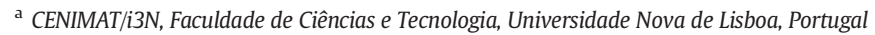 \\ b UNIDEMI, Faculdade de Ciências e Tecnologia, Universidade Nova de Lisboa, Portugal \\ c Institute of Materials Research, Helmholtz-Zentrum Geesthacht, Max-Planck-Str. 1, D-21502 Geesthacht, Germany \\ d Centro Láser UPM, Universidad Politécnica de Madrid, Edificio “La Arboleda”, Ctra. Valencia, km 7,300, Campus Sur UPM, 28031 Madrid, Spain
}

\section{A R T I C L E I N F O}

\section{Article history:}

Received 26 December 2015

Received in revised form 23 March 2016

Accepted 26 March 2016

Available online xxxx

\section{Keywords:}

NiTi shape memory alloys

Laser welding

Residual stress

Rietveld refinement

Synchrotron radiation

\begin{abstract}
A B S T R A C T
Synchrotron radiation was used for fine probing the different regions of a laser welded NiTi joint. Measurements 19 were taken at $0.2 \mathrm{~mm}$ intervals, starting in the non-thermal affected material, through the heat affected zone, the 20 fusion zone and again across the heat affected zone finishing in the base material. Along the longitudinal direction 21 the residual stresses were found to be always tensile in the heat affected and fusion zones; along the transversal 22 direction, an inversion of the stress states was found. The magnitude of the residual stresses was found to be more 23 significant in the transversal direction due to constraints imposed during welding. The heat introduced during 24 welding has a stress relief effect on the cold-rolled base material, although it does not promote any solid-state 25 transformation. The effect of the heat input on the residual stress pattern and magnitude was identified and it 26 was seen that high heat input leads to a higher magnitude of the residual stresses in the weld and the stress relief 27 effect is observed over a larger extension from the weld centerline. This paper presents the first experimental 28 study on the determination of residual stresses on laser welded NiTi shape memory alloys.
\end{abstract}

\section{Introduction}

NiTi shape memory alloys are stimulus-responsive materials which present both superelasticity and shape memory effect [1,2]. Laser welding of NiTi shape memory alloys has widespread rapidly over the last years. Several works report the effect of laser welding on the mechanical and functional properties of the welded joints [3-8]. It is a well-accepted fact that, after laser welding, the material presents a decrease in the mechanical properties when compared to the base material $[4,9]$. The presence of precipitates in the fusion zone, such as $\mathrm{Ti}_{2} \mathrm{Ni}$, is pointed out as a reason for the decreased in ductility of the welded material $[9,10]$.

In fusion based welding processes, such as laser, the gradient of peak temperature followed by a variation in heating and cooling rates along a weld induces residual stresses in the weld region and its neighborhood $[11,12]$. The welding residual stress field depends on a variety of factors such as: material properties, welding process parameters, pre-heating temperature (if any) and dimensions of the structure to be welded as well as imposed external restrain conditions [13]. Residual stresses may give origin to distortions in the welded material, and these may cause premature failure during service $[14,15]$.

Residual stresses can occur due to a structural mismatch or by an uneven distribution of nonelastic strains. Thermal stresses occur in welding due to a localization of the heating source which originates

\footnotetext{
* Corresponding author.

E-mail address: jp.oliveira@campus.fct.unl.pt (J.P. Oliveira).
}

non uniform temperature distributions in the weld itself and surround- 64 ing medium [16]. Additionally, the molten zone shrinks during solidifi- 65 cation and this shrinkage is constrained by the surrounding cooler 66 material [17]. If any phase transformations, with associated volume 67 change, occur during cooling, it is possible to compensate the tensile 68 contraction stresses that occur in the fusion zone, provided that the 69 phase transformation is associated with a volume expansion and not 70 contraction.

Considering a stress-free base material it is expected that, after 72 welding, the heat affected zone presents compressive stresses, while 73 in the fusion zone tensile stresses should be found. This can be ex- 74 plained based on the "Three-bar Arrangement Theory" [18]: consider 75 three similar metal bars, all at room temperature, connected by two 76 rigid blocks. The bar located in the middle is heated up. However, its 77 thermal expansion is restrained by the other two side bars. As such, 78 compressive stresses are developed in the middle bar (while the side 79 bars are in tension) and increase with increasing temperature. When 80 heating stops and the middle bar is allowed to cool down, its thermal 81 contraction is restrained again by the side bars. Then, the stress state 82 is reversed: the middle bar is under tensile stress and the side bars 83 under compressive stresses. Comparing to the different regions of the 84 welded material, the middle bar acts as the fusion zone and the side 85 bars as the heat affected zone. Fig. 1 depicts the expected residual stress- 86 es in these regions of the weld. In the non-thermally affected base ma- 87 terial the development of residual stresses is not expected.

It must be noticed that residual stresses are always present after 89 welding. In case of large structures post-weld heat treatments are 90 


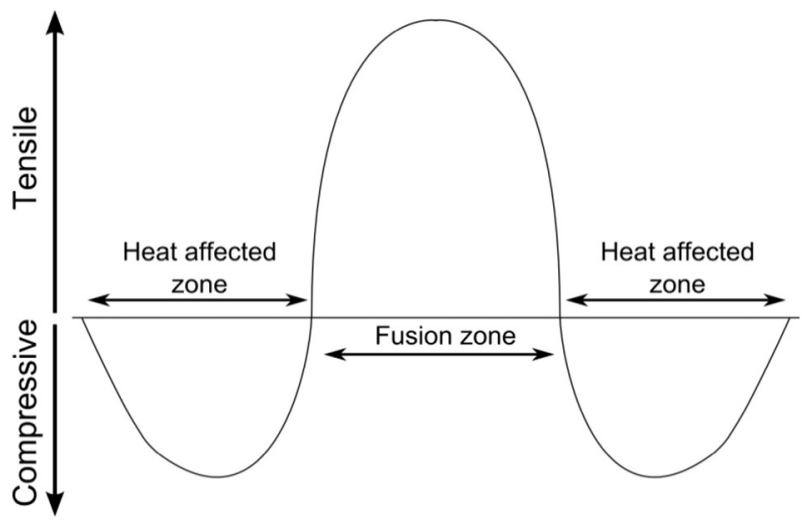

Fig. 1. Expected residual stresses in the heat affected and fusion zones after welding.

performed so that the yield stress decreases and the residual stresses left on the structure are of the order of magnitude of the yield strength of the material at the temperature of the heat treatment, decreasing their magnitude and increasing the joints mechanical performance $[19,20]$.

Measuring residual stresses by X-ray diffraction methods is a precision reliable technique. These measurements can be performed either with laboratorial sources (low energy X-rays) or in dedicated facilities, known as storage rings, with high energy X-rays. The former are used to determine the residual stresses in a restrict thickness of the welded samples due to its low energy and, hence, its low material penetration. In opposition, in synchrotron facilities the same analysis can be performed throughout the material, as its energy is considerably higher (up to $300 \mathrm{keV}$ ). The use of these hard X-ray sources allows for a greater penetration in the analyzed samples, thus it is possible to work in transmission mode even when using thick samples (up to $10 \mathrm{~mm}$, for example). Other advantages of the use of synchrotron radiation include the very fast acquisition time (below the millisecond range if necessary) and the ability to decrease the analyzed spot size while keeping an intense beam (high photon flux). The capabilities of using synchrotron radiation, for fine probing of materials joining was, recently, observed by Cavaleiro et al. [21] in self propagated diffusion joining of NiTi.

Although it is usual to analyze the effect of the welding process on the residual stresses of the welded joints [22-24], no such work was yet performed in laser welded NiTi shape memory alloys. As such, there is a gap in research that needs to be filled for this specific class of functional materials. Due to the intrinsic characteristics of laser welding (high energy density with reduced width of the thermally affected zones) analysis of the different regions by X-ray diffraction requires precise control of the beam dimension and its positioning in the weld. Synchrotron X-ray diffraction was carried out for such analysis, as the radiation beam is very small, has a high photon flux, and can be precisely directed to the different regions of the weld.

In this work, X-ray synchrotron radiation was used to probe laser welded NiTi samples from the base material to the fusion zone using a beam with a cross section of $200 \times 200 \mu \mathrm{m}$. The calculation of the residual stresses was performed using Rietveld analysis with MAUD.

\section{Experimental procedure}

Plates $1 \mathrm{~mm}$ thick of $50.8 \mathrm{Ni}$-Ti (at.\%) shape memory alloy, supplied by Memry in the flat annealed condition, were used. To characterize the structural transformation temperature of the base material, Differential Scanning Calorimetry (DSC) was used. The temperature range was set between -160 and $70{ }^{\circ} \mathrm{C}$. Both cooling and heating rates were set at $10 \mathrm{~K} / \mathrm{min}$. From these measurements it was confirmed that the base material was fully austenitic at room temperature (Fig. 2).

A Nd:YAG laser, operating in continuous wave mode, from Rofin Sinar was used for laser butt joining the plates. Prior to welding, the samples

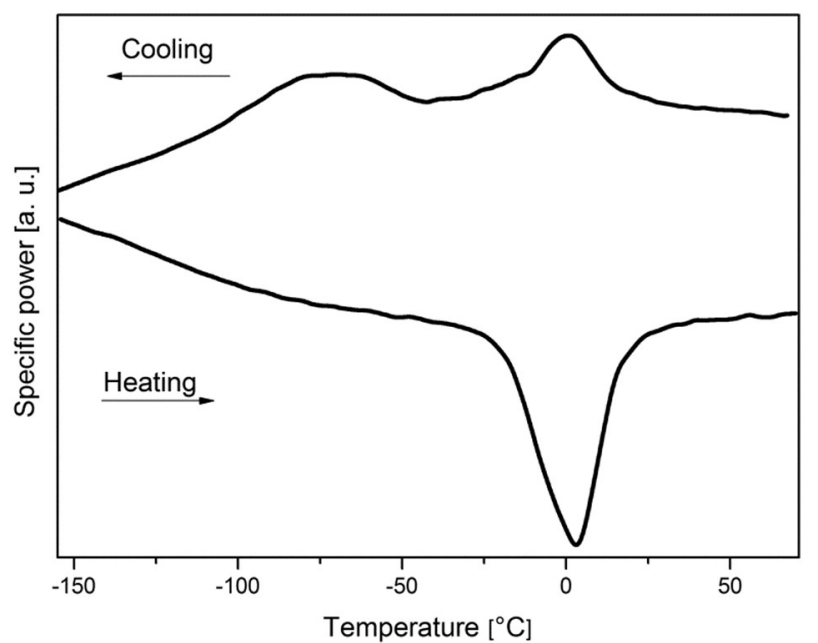

Fig. 2. DSC measurement of base material.

were cut using a precision cutting machine into $30 \times 30 \mathrm{sq} \mathrm{mm}$ and 138 cleaned with alcohol and acetone. Two welding conditions were selected 139 and are presented in Table 1. These parameters were chosen in order to 140 obtain full penetration joints, without defects, but with significantly dif- 141 ferent heat inputs. Argon and helium were used as shielding gases on 142 the face and on the root, respectively, to prevent oxidation. 143

Microstructure of the welded joints (Fig. 3) revealed that heat affect- 144 ed zone was constituted by coarser equiaxed grains when compared to 145 the base material. From the favorable oriented grains in the heat affect- 146 ed zone, columnar epitaxial grains grew in the fusion zone. 147

X-ray diffraction was performed at beamline P07 High Energy Mate- 148 rials Science (HEMS) of Petra III/DESY, using a wavelength of $0.1426 \AA 149$ ( $87 \mathrm{keV}$ ) and a 2D detector Mar345 placed at $1.35 \mathrm{~m}$ from the sample. 150 The pixel size of the detector was of $200 \times 200 \mu \mathrm{m}$ and the correspond- 151 ing accuracy of the measured $2 \Theta$ angle was of $0.0084^{\circ}$. A probing line, 152 perpendicular to the weld bead, started and ended in the base material, 153 $3 \mathrm{~mm}$ away from the weld centerline, passing through the heat affected 154 zone and the fusion zone.

155

The experimental setup using during the X-ray diffraction experi- 156 ments is depicted in Fig. 4. Based on the sample orientation in terms 157 of laboratory referential (Fig. 4), the azimuthal angle, $\varphi \phi$, is defined as 158 equal to $0^{\circ}$ in the longitudinal direction of the weld bead and equal to 159 $90^{\circ}$ for the transversal direction (perpendicular to the weld bead). $\quad 160$

Throughout the experiments, performed at room temperature, com- 161 plete Debye-Scherrer diffraction rings were obtained (Fig. 5). 162

For residual stress analysis, Rietveld code implemented in MAUD 163 [25] was used following a similar procedure as described in [26]. During 164 Rietveld refinement, parameters such as background, intensity, profile 165 shape, unit cell, texture and stress model were refined. For the Rietveld 166 analysis, four austenite peaks were considered: (100), (110), (111) and 167 (200). When both austenite and martensite were present, five addition- 168 al martensite peaks were considered: (101), (110), (1111), (020) and 169 (211). These peaks used for Rietveld analysis are shown in Fig. 6. During 170 the Rietveld analysis performed in MAUD, integration in $5^{\circ}$ steps along 171 the azimuthal angle was performed. The mechanical properties of 172 both phases used in the stress model are described in $[27,28]$.

Table 1

Laser welding parameters.

\begin{tabular}{|c|c|c|c|}
\hline Sample & Power $[\mathrm{W}]$ & Welding speed [mm/s] & Heat input $[\mathrm{J} / \mathrm{cm}]$ \\
\hline A & 990 & 25 & 396 \\
\hline B & 1485 & 20 & 743 \\
\hline
\end{tabular}


a)

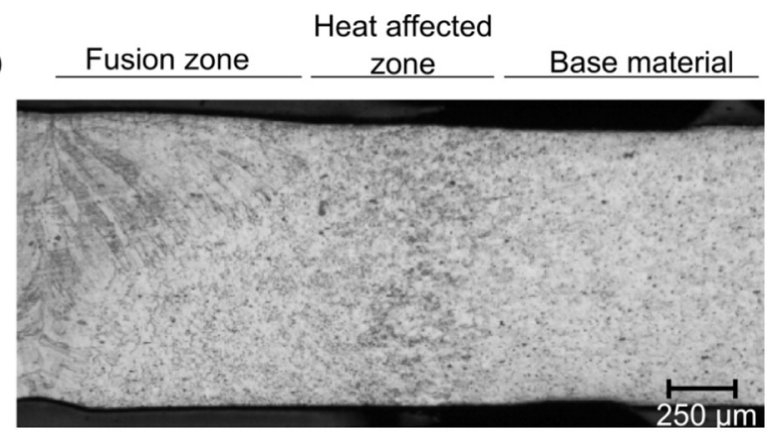

b)

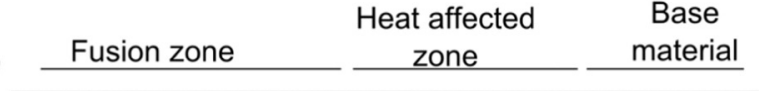

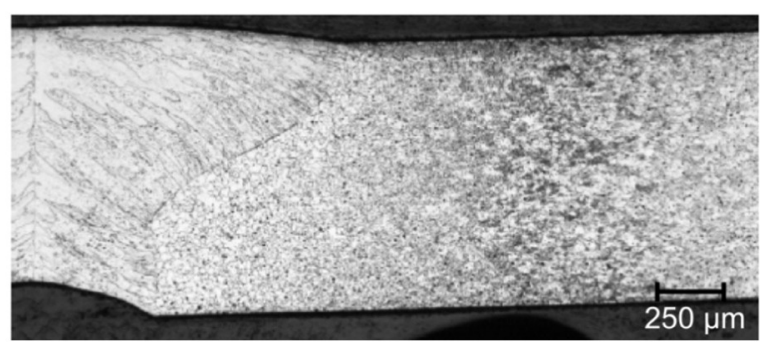

Fig. 3. Microstructure of the welded joints: a) sample A; b) sample B.

Following other authors [29] that have made similar assumptions when performing residual stress analysis using X-ray diffraction, a plane-stress condition was assumed owing to the reduced thickness of the material $(1 \mathrm{~mm})$.

According to the configuration used during X-ray diffraction experiments (Fig. 4), the principal directions of the system are:

- $\mathrm{x}$ component, along the longitudinal direction to the weld bead;

- y component, perpendicular to the weld bead;

- $\mathrm{z}$ component, normal to the material surface.

As a plane-stress condition is assumed, the principal stress along the principal direction $z, \sigma_{Z}$, will be null, while the remaining principal stresses, $\sigma_{\mathrm{X}}$ and $\sigma_{\mathrm{Y}}$, can be calculated through Rietveld 186 refinement.

\section{Results and discussion}

188

Fit2D [30] was used to analyze the diffraction images in the $2 \Theta$ range 189 from 3.4 to $4.2^{\circ}$. For obtaining the X-ray diffraction patterns correspon- 190 dent to each analyzed spot, the raw diffraction images were integrated 191 along the full azimuthal angle $\varphi$. As such, it was possible to perform a 192 microstructural characterization of the existing phases in the different 193 regions of the welds. Fig. 7 depicts the superimposition of the 194 diffractograms obtained for samples A and B. It is observed, that, in 195 the former, the base material was fully austenitic, but the heat affected 196 and the fusion zones showed austenite and martensite, the latter 197 being present at room temperature due to the welding thermal cycle. 198 Sample B had also austenite and martensite in the thermally affected 199 zones, but the extension of each region was slightly larger due to the 200 higher heat input introduced in this weld.

201

The variation of the $2 \theta$ peak position of (110) austenite peak, which 202 is the most intense for the NiTi system, in welds A and B, in three distinct 203 regions of the weld (base material, heat affected and fusion zones) is 204 depicted in Fig. 8. Fig. 8a and d, correspond to the base material and 205 show that the $2 \theta$ position of the (110) austenite peak does not vary sig- 206 nificantly along the azimuthal angle. However, in the heat affected zone 207 (Fig. $8 \mathrm{~b}$ and e) the variation is more notorious and is impaired in the fu- 208 sion zone (Fig. 8c and f). It must be noticed that in the thermally affected 209 zones a coarse grain structure is observed due to grain growth at high 210 temperature. These coarse grains cause high intensity peaks.

211

After Rietveld refinement, good agreement in position, width and in- 212 tensity between the calculated and experimental patterns was observed 213 (Fig. 9), indicating a good fitting.

214

The calculated principal residual stresses, $\sigma_{\mathrm{X}}$ and $\sigma_{\mathrm{Y}}$, for the welded 215 samples are depicted in Fig. 10.

Considering both samples, the $\sigma_{\mathrm{X}}$ residual stress in the heat affected 217 zone range from roughly 10 to $105 \mathrm{MPa}$, while in the fusion zone the re- 218 sidual stresses reach up to $135 \mathrm{MPa}$ for the sample welded with the 219 highest heat input. It can be observed an inversion of the stress state 220 when approaching the fusion zone from the heat affected zone: the $\sigma_{Y} 221$ residual stresses are always compressive in the heat affected zone and 222 range between 20 and $60 \mathrm{MPa}$ in the fusion zone.

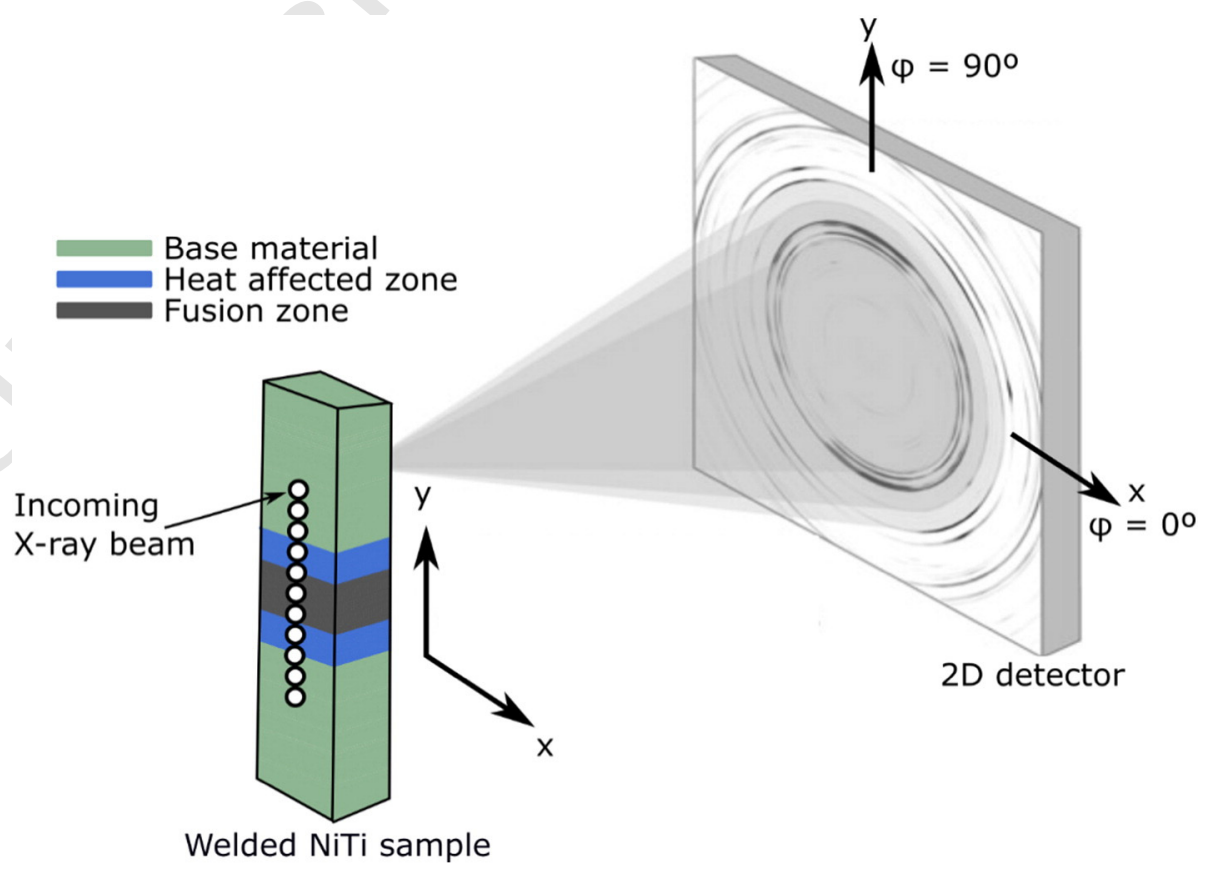

Fig. 4. Experimental setup for the X-ray diffraction experiments (not to scale): 3D schematic view. 
a)

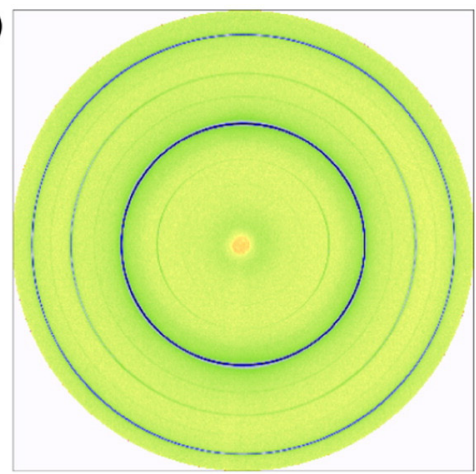

b)

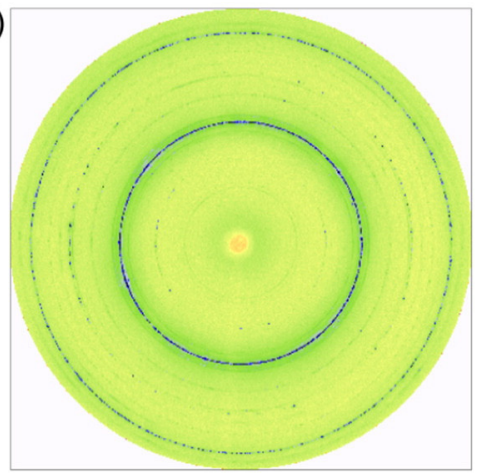

c)

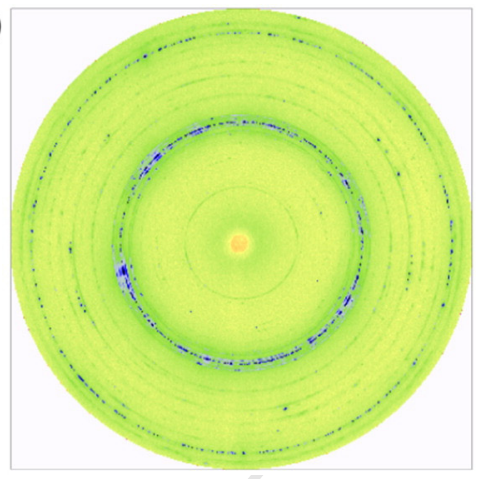

Fig. 5. Typical Debye-Scherrer rings for laser welded NiTi: a) base material, b) heat affected zone, c) fusion zone.

The inversion of the residual stress conditions in the principal directions, measured in the heat affected and fusion zones was also reported for other materials, such as steels [31]. The base material presented also residual stresses originated during its manufacturing process. It can also be observed that the distribution of the residual stresses in the material is symmetric relative to the weld centerline axis, which is characteristic of laser welding with a top hat or Gaussian beam profiles.

Comparing the residual stresses along the principal directions for the same welded sample, it can be observed that the absolute value of the residual stresses is higher along the $\mathrm{y}$ axis than along the $\mathrm{x}$ axis. This is due to the fact that, during welding, a constraint was applied along this direction in order to guarantee a good fit-up throughout the full weld length. As such, the material was not able to move freely, generating residual thermal stresses along this direction.

Of particular interest is the stress relief phenomenon observed for the principal stress $\sigma_{\mathrm{Y}}$ in the base material, marked in Fig. 10. Similarly, along the other principal direction ( $\mathrm{x}$ axis), the same feature is ob- 240 served. The reason for this behavior is related to the fact that, along 241 the transversal direction (y axis), there is a decrease in the tensile 242 stresses in the work-hardened base material. Since no distortions 243 were observed after welding, this means that an overall equilibrium 244 was achieved, justifying the inversion of the stress state in the base ma- 245 terial along the longitudinal direction. In the base material, the occur- 246 rence of microstructural modifications was not expected as the 247 maximum temperatures reached are below those needed to induce 248 any precipitation and/or recrystallization phenomena. This stress relief 249 of the work-hardened base material occurs in the regions that have 250 been heated up to temperatures below $350{ }^{\circ} \mathrm{C}$. As a consequence, the re- 251 sidual stresses magnitude in this region decreases due to the fusion 252 welding process, reverting the effect of cold working without changing 253 the grain structure of the material [32]. In the regions heated above 254 $350{ }^{\circ} \mathrm{C}$, Ni-rich precipitates, such as $\mathrm{Ni}_{4} \mathrm{Ti}_{3}$, may be formed for time 255

a)

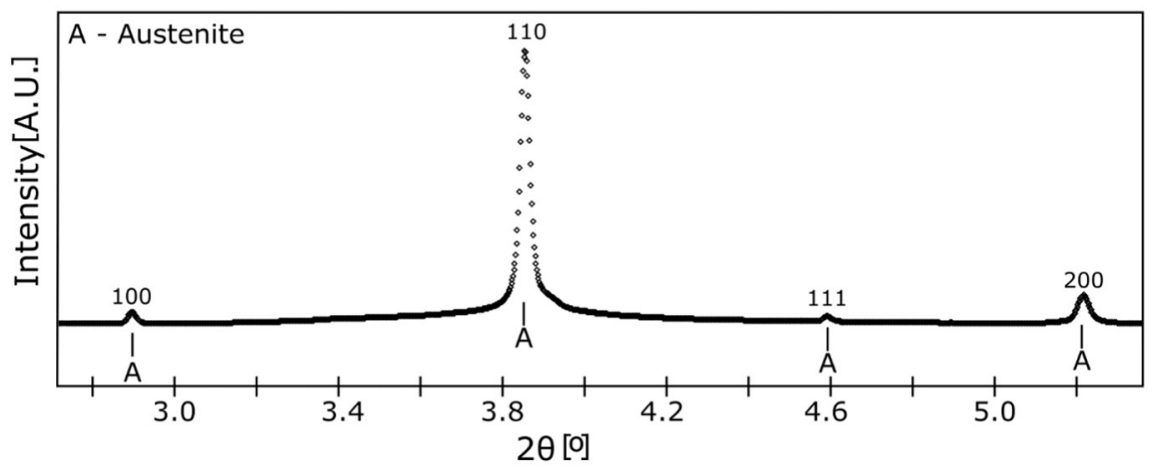

b)

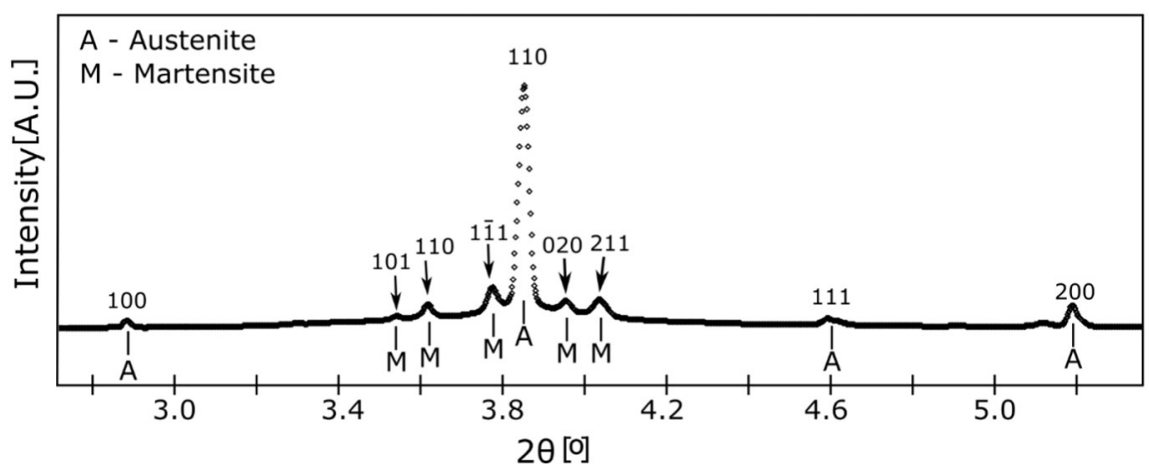

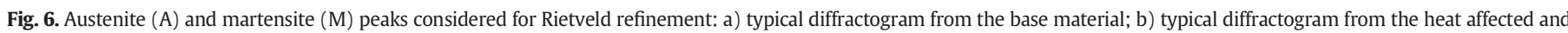
fusion zones. 

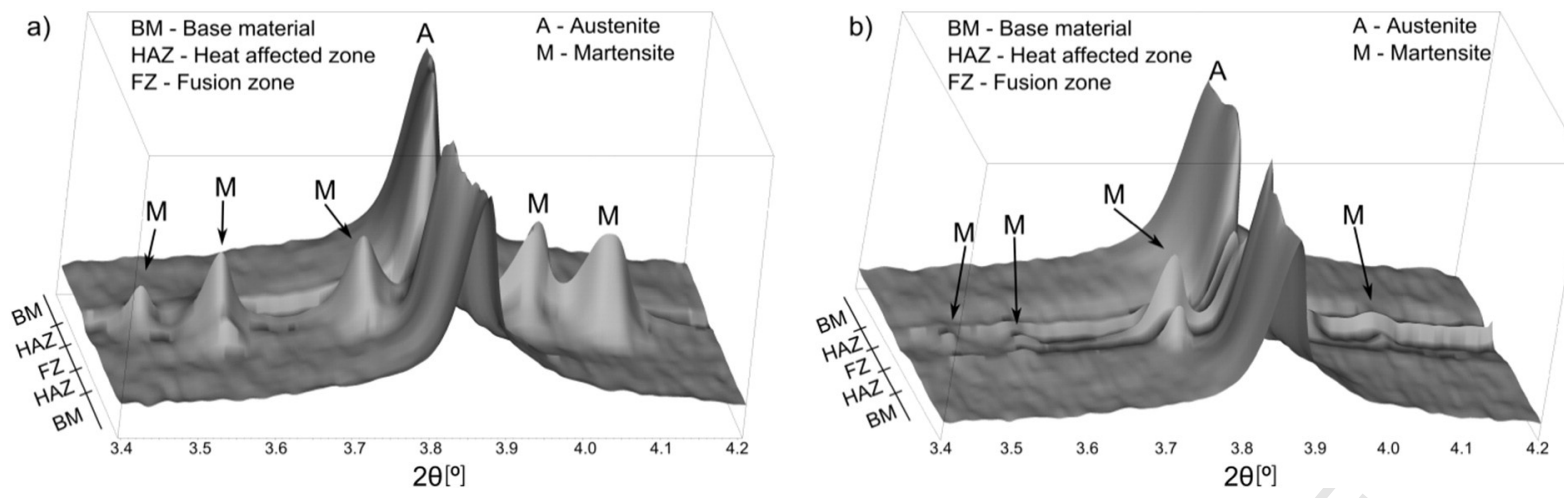

Fig. 7. 3D stacking of the diffractograms performed on laser welds: a) sample A; b) sample B.

lapses in the order of a few seconds [33], increasing the transformation temperatures, thus leading to the presence of martensite at room temperature.

In order to understand the feasibility of the welding procedure to promote the aforementioned stress relief phenomenon, the peak temperatures in the base material were computed based on the 2D solution of the Rosenthal equation:

$\mathrm{T}-\mathrm{T}_{0}=\frac{\mathrm{Q}}{2 \pi \mathrm{kg}} \mathrm{e}^{(\mathrm{vx} / 2 \alpha)} \mathrm{K} 0\left[\frac{\mathrm{v} \mathrm{R}}{2 \alpha}\right]$

where:

$\mathrm{T}$, is the peak temperature at a distance $\mathrm{x}$ in the $(\mathrm{x}, \mathrm{y})$ plane $(\mathrm{K})$;

$\mathrm{T}_{0}$, is the room temperature $(\mathrm{K})$;

$\mathrm{Q}$ is the heat input $(\mathrm{J} / \mathrm{m})$.

$\mathrm{k}$, is the thermal conductivity $\left(\mathrm{W} \mathrm{m}^{-1} \mathrm{~K}^{-1}\right)$;

$\mathrm{g}$, is the plate thickness $(\mathrm{m})$;

$\mathrm{v}$, is the welding speed $\left(\mathrm{m} \mathrm{s}^{-1}\right)$;

$\alpha$, is the thermal diffusivity $\left(\left(\mathrm{m}^{2} \mathrm{~s}^{-1}\right)\right.$;
$\mathrm{K} 0$, is a modified Bessel function of the second kind and zero order; 271 $\mathrm{R}$, is the radial distance $\left(\mathrm{R}=\sqrt{\mathrm{x}^{2}+\mathrm{y}^{2}}\right)(\mathrm{m})$.

Both $\mathrm{x}$ and $\mathrm{y}$ directions were defined as in Fig. 4. Fig. 11, depicts the 273 peak temperature variation as a function of the distance to the weld 274 centerline along the y direction for welds A and B. It can be observed, 275 that the distance from the weld centerline at which the temperature 276 range is between 200 and $350{ }^{\circ} \mathrm{C}$ (for promoting the stress relief phe- 277 nomenon), is similar to those obtained from the X-ray diffraction mea- 278 surements, thus validating this assumption.

279

The effect of the higher heat input in sample B, gives rise to a higher 280 magnitude of the residual stresses in the different regions of the weld 281 (heat affected zone and fusion zone), in either the principal directions, 282 when compared to sample A. A similar effect of the heat input on the 283 magnitude of the residual stresses was observed by other authors [34]. 284 This can be explained using the "Three-bar Arrangement Theory" de- 285 scribed in the introduction.

Another interesting consequence of the higher heat input intro- 287 duced in sample B is that the stress relieving phenomena in the base 288 material occurs at a longer distance from the weld centerline, when 289
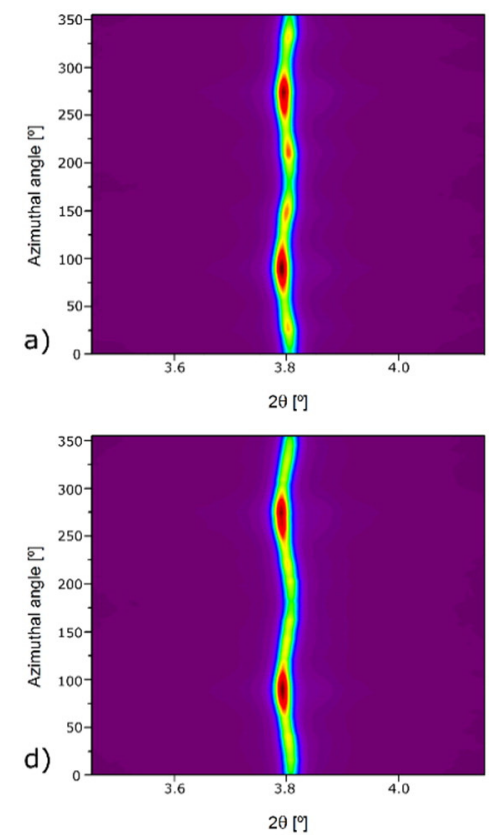

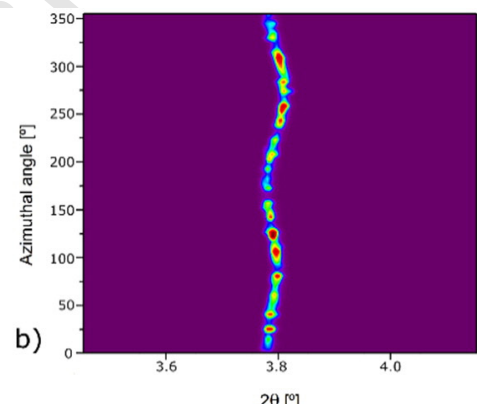

$\left.2 \theta^{\circ}\right]$

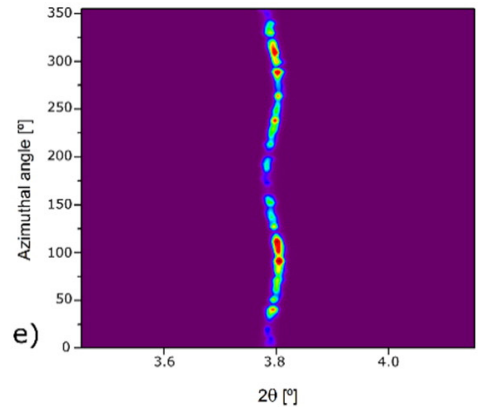

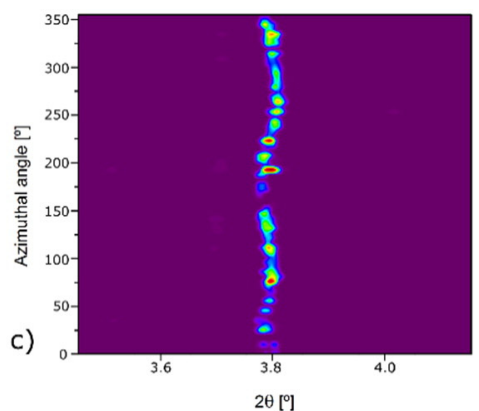
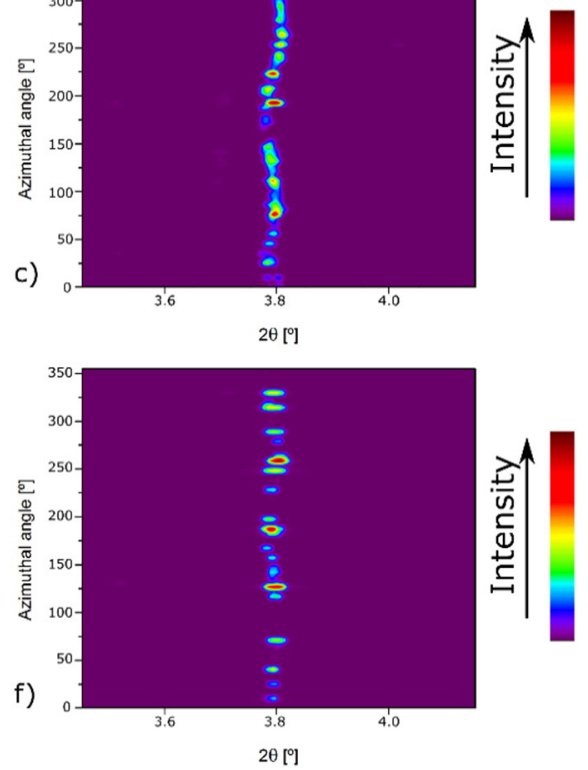

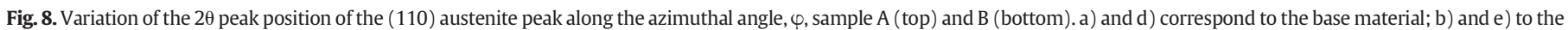
heat affected zone and c) and f) to the fusion zone. 


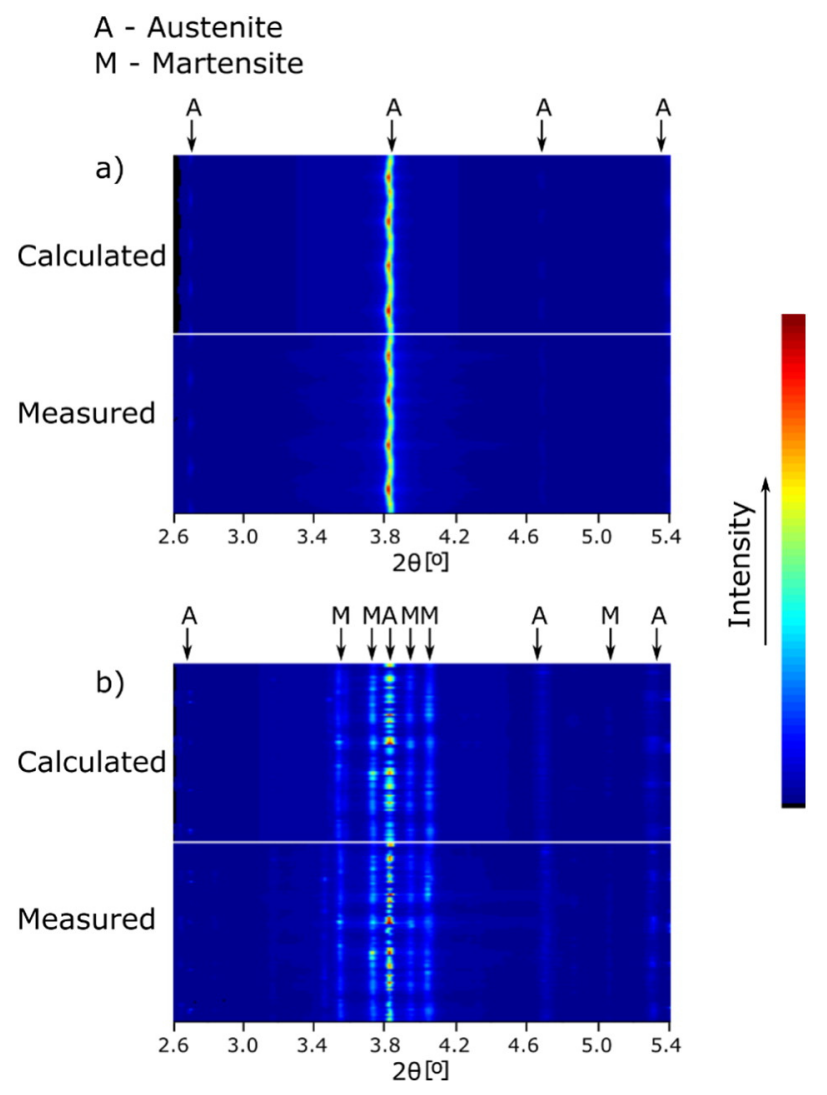

Fig. 9. Calculated and measured diffraction patterns: a) in the base material where only austenite (A) exists; b) in the fusion zone where both austenite and martensite (M) are present. compared to sample A. This effect is evident in Fig. 10, where the stress relief phenomenon is seen to occur in a region about $0.2 \mathrm{~mm}$ wider than in sample A: higher heat input allows for a more extended heat propagation in the base material, which, in turn promotes the stress relieving phenomena. Additionally, the higher heat input originates a higher extension of the thermally affected regions.

From the principal stresses calculated using the Rietveld method, the von Mises stresses can also be obtained [35]. The evolution of the von Mises stresses along the welded materials is depicted in Fig. 12. In a localized narrow region of the heat affected zone, the von Mises stress reaches a maximum value of $375 \mathrm{MPa}$. Previous results [8,36] have shown that the critical stress for the martensitic transformation for laser welding of NiTi range between 335 and $375 \mathrm{MPa}$. However, in

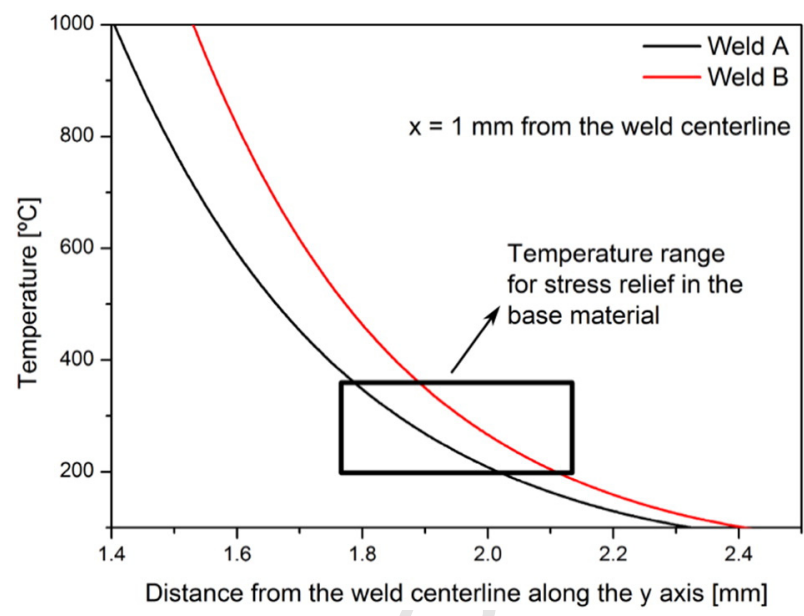

Fig. 11. Peak temperatures, from the weld centerline along the y axis, at a fixed distance of $\mathrm{x}=1 \mathrm{~mm}$ from the weld centerline. The black box represents the temperature range where stress relief phenomenon may occur.

the remaining regions of the welded material the von Mises stresses 303 are below this range.

304

The residual stresses were also measured for the martensite in both 305 the heat affected and fusion zones, where this phase was observed. 306 However, the residual stresses calculated for this phase ranged between 307 -6 and $8 \mathrm{MPa}$, which can be negligible considering the magnitude of 308 the residual stresses found for the austenitic phase. The reason for this 309 to occur is related to the mechanical properties of austenitic and mar- 310 tensitic NiTi. The former has a higher Young's modulus than the latter. 311 As such, the load will be predominantly transferred to the "harder" ma- 312 terial, which is austenite in this case. Additionally, martensitic NiTi has a 313 lower constant stress plateau than austenitic NiTi, which enables stress 314 relaxation of the neighboring austenite. Similar behavior was also re- 315 ported to occur for Cu-based shape memory alloys [37].

No distortions were observed after butt welding the NiTi plates. This 317 is related to the fact that the global residual stresses along the material 318 are in equilibrium.

It is possible to alter the residual stresses within a welded joint by 320 applying proper post-weld heat treatments. The effect of different 321 post-weld heat treatments on the distribution of the residual stresses 322 in laser welded NiTi joints is currently under study.

\section{Conclusions}

324

The first experimental study for the determination of residual stress 325 in laser welded NiTi shape memory alloys is presented. For this, 326
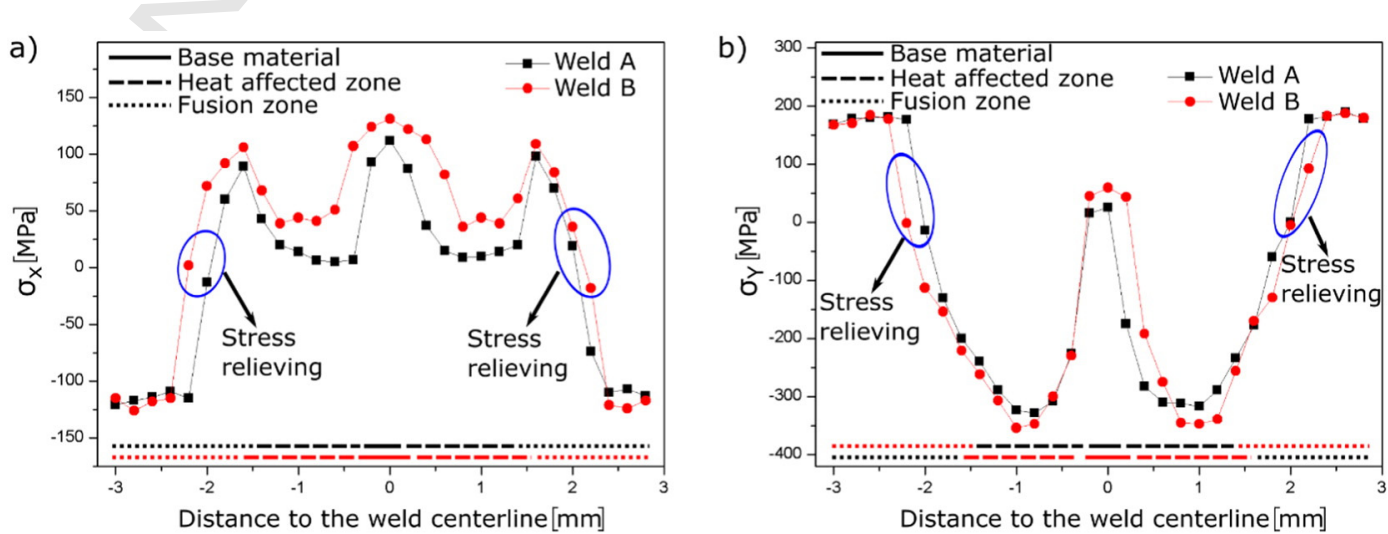

Fig. 10. Calculated residual stress for welds $A$ and $\left.B: a) \sigma_{X}, b\right) \sigma_{Y}$. 


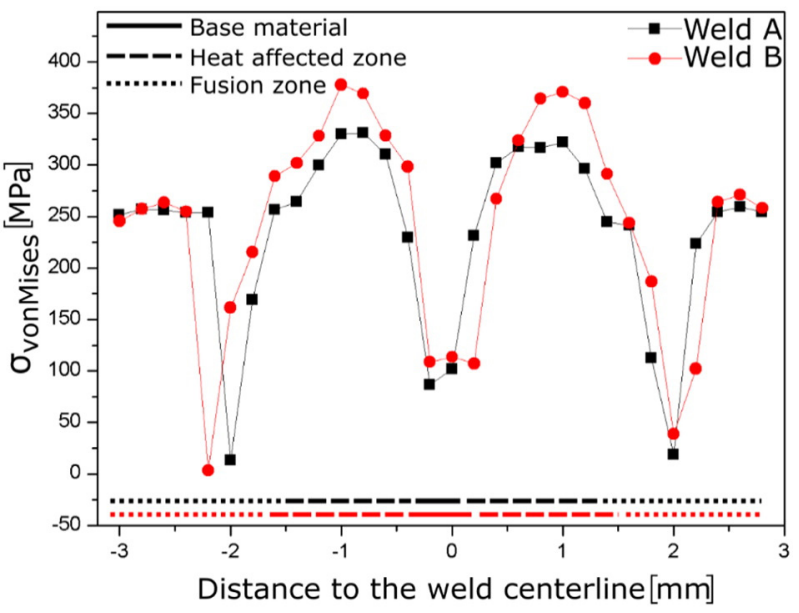

Fig. 12. von Mises stresses along the welded materials.

synchrotron radiation based X-ray diffraction and this data was exploited with Rietveld analysis. The following can be concluded:

- The principal stresses along the $\mathrm{x}$ axis were found to fall within the range of 10 to $105 \mathrm{MPa}$ in the heat affected zone, while in the fusion zone they increase up to $135 \mathrm{MPa}$. The $\sigma_{\mathrm{Y}}$ residual stresses were found to be always compressive in the heat affected zone, while in the fusion zone there is a tensile stress state with a magnitude ranging from 20 to $60 \mathrm{MPa}$.

- The inversion of the stress states in the different regions of the weld (heat affected and fusion zones) is in good agreement with general welding thermo-mechanical analysis.

- The heat input introduced in the welds promoted stress relief phenomena on the work-hardened base material. As such, the residual stresses in this region decreased.

- Stress relieving phenomena on the base material occur at temperatures below $350{ }^{\circ} \mathrm{C}$.

- Higher heat inputs originate higher magnitude of the residual stresses, in absolute modulus, in the heat affected and fusion zones.

- No distortions were observed after welding and this results from an overall near equilibrium stress state.

\section{Acknowledgments}

JPO and FBF acknowledge funding of CENIMAT/I3N by FEDER funds through the COMPETE 2020 Program and National Funds through FCT - Portuguese Foundation for Science and Technology under the project UID/CTM/50025/2013. RMM acknowledges funding of UNIDEMI by FEDER funds through the COMPETE 2020 Program and National Funds through FCT - Portuguese Foundation for Science and Technology under the project UID/EMS/00667/2013. The authors acknowledge DESY and HZG for beam time and travel reimbursement under proposal I-20120563 EC FP7/2007-2013 grant agreement no. 312284. JPO acknowledges FCT/MCTES for funding PhD grant SFRH/BD/85047/2012. The authors acknowledge useful discussions with Professor Luca Lutterotti, developer of MAUD.

\section{References}

[1] L. Sun, W.M. Huang, Z. Ding, Y. Zhao, C.C. Wang, H. Purnawali, et al., Stimulus-responsive shape memory materials: a review, Mater. Des. 33 (2012) 577-640, http://dx.doi.org/10. 1016/j.matdes.2011.04.065.

[2] J.M. Jani, M. Leary, A. Subic, M.a. Gibson, A review of shape memory alloy research, applications and opportunities, Mater. Des. 56 (2014) 1078-1113, http://dx.doi.org/10.1016/j. matdes.2013.11.084.
[3] A. Tuissi, S. Besseghini, T. Ranucci, F. Squatrito, M. Pozzi, Effect of Nd-YAG laser welding on 368 the functional properties of the Ni-49.6 at\%Ti, Mater. Sci. Eng. A 273-275 (1999) 813-817, 369 http://dx.doi.org/10.1016/S0921-5093(99)00422-0.

[4] Y.T. Hsu, Y.R. Wang, S.K. Wu, C. Chen, Effect of CO2 laser welding on the shape-memory 371 and corrosion characteristics of TiNi alloys, Metall. Mater. Trans. A 32 (2001) 569-576, 372 http://dx.doi.org/10.1007/s11661-001-0073-2.

[5] A. Falvo, F.M. Furgiuele, C. Maletta, Functional behaviour of a NiTi-welded joint: two-way 374 shape memory effect, Mater. Sci. Eng. A 481-482 (2008) 647-650, http://dx.doi.org/10. 375 1016/j.msea.2006.11.178.

[6] H. Gugel, A. Schuermann, W. Theisen, Laser welding of NiTi wires, Mater. Sci. Eng. A 481- 377 482 (2008) 668-671, http://dx.doi.org/10.1016/j.msea.2006.11.179.

[7] J.P. Oliveira, F.M.B. Fernandes, N. Schell, R.M. Miranda, Shape memory effect of laser 379 welded NiTi plates, Funct. Mater. Lett. 08 (2015) 1550069, http://dx.doi.org/10.1142/ 380 S1793604715500691.

[8] J.P. Oliveira, R.M. Miranda, N. Schell, F.M. Braz Fernandes, High strain and long duration cy- 382 cling behavior of laser welded NiTi sheets, Int. J. Fatigue 83 (2016) 195-200, http://dx.doi. 383 org/10.1016/j.ijfatigue.2015.10.013.

[9] P. Schlossmacher, T. Haas, A.S. Ussler, Laser-welding of a Ni-rich TiNi shape memory alloy: 385 mechanical behavior, J. Phys. IV 07 (1997), http://dx.doi.org/10.1051/jp4:1997539 386 (C5-251 - C5-256)

[10] A. Tuissi, P. Bassani, M. Gerosa, D. Mauri, M. Pini, E. Capello, et al., CO2 laser welding of 388 NiTi/Ni-based alloys, in: A. Pelton, T. Duerig (Eds.),Proc. Int. Conf. Shape Mem. Superelastic 389 Technol. 2004, pp. 229-238, http://dx.doi.org/10.1361/cp2003smst229.

[11] T.-L. Teng, C.-C. Lin, Effect of welding conditions on residual stresses due to butt welds, Int. J. 391 Press. Vessel. Pip. 75 (1998) 857-864, http://dx.doi.org/10.1016/S0308-0161(98)00084-2. 392

[12] J. Rahman Chukkan, M. Vasudevan, S. Muthukumaran, R. Ravi Kumar, N. Chandrasekhar, 393 Simulation of laser butt welding of AISI 316L stainless steel sheet using various heat 394 sources and experimental validation, J. Mater. Process. Technol. 219 (2015) 48-59, 395 http://dx.doi.org/10.1016/j.jmatprotec.2014.12.008.

[13] D. Deng, H. Murakawa, W. Liang, Numerical and experimental investigations on welding 397 residual stress in multi-pass butt-welded austenitic stainless steel pipe, Comput. Mater. 398 Sci. 42 (2008) 234-244, http://dx.doi.org/10.1016/j.commatsci.2007.07.009.

[14] K. Masubuchi, Analysis of Welded Structures, first ed. Pergamon Press, Oxford, 1980 properties of different steel grades on welding residual stresses and angular distortion. 402 Mater. Des. 2015;65:878-89. doi:http://dx.doi.org/10.1016/j.matdes.2014.10.019. 403

[16] A. Lienert, T. Siewert, S. Babu, V. Acoff, ASM Handbook, Volume 6A, Welding Fundamentals 404 and Processes, first ed. ASM International, Ohio, 2011.

[17] R.S. Coelho, M. Corpas, J.A. Moreto, A. Jahn, J. Standfuß, A. Kaysser-Pyzalla, et al., Induction- 406 assisted laser beam welding of a thermomechanically rolled HSLA S500MC steel: a micro- 407 structure and residual stress assessment, Mater. Sci. Eng. A 578 (2013) 125-133, http://dx. 408 doi.org/10.1016/j.msea.2013.04.039.

[18] S. Kou, Welding Metallurgy, second ed. John Wiley \& Sons, Inc., Hoboken, 2002, http://dx. 410 doi.org/10.1002/0471434027.

[19] J.R. Cho, B.Y. Lee, Y.H. Moon, C.J. Van Tyne, Investigation of residual stress and post weld 412 heat treatment of multi-pass welds by finite element method and experiments, J. Mater. 413 Process. Technol. 155-156 (2004) 1690-1695, http://dx.doi.org/10.1016/j.jmatprotec. 414 2004.04.325.

[20] A.H. Yaghi, T.H. Hyde, A.A. Becker, W. Sun, Finite element simulation of welding and resid- 416 ual stresses in a P91 steel pipe incorporating solid-state phase transformation and post- 417 weld heat treatment, J. Strain Anal. Eng. Des. 43 (2008) 275-293, http://dx.doi.org/10. 418 1243/03093247JSA372.

[21] A.J. Cavaleiro, A.S. Ramos, F.M. Braz Fernandes, N. Schell, M.T. Vieira, In situ characterization of 420 $\mathrm{NiTi} / \mathrm{Ti} 6 \mathrm{Al} 4 \mathrm{~V}$ joints during reaction-assisted diffusion bonding using Ni/Ti multilayers, J. Mater. 421 Eng. Perform. 23 (2014) 1625-1629, http://dx.doi.org/10.1007/s11665-014-0930-y. . 422

[22] B. Brickstad, B.L. Josefson, A parametric study of residual stresses in multi-pass butt- 423 welded stainless steel pipes, Int. J. Press. Vessel. Pip. 75 (1998) 11-25, http://dx.doi.org/ 424 10.1016/S0308-0161(97)00117-8.

[23] T.A. Mai, A.C. Spowage, Characterisation of dissimilar joints in laser welding of steel-kovar, 426 copper-steel and copper-aluminium, Mater. Sci. Eng. A 374 (2004) 224-233, http://dx. 427 doi.org/10.1016/j.msea.2004.02.025

[24] D. Deng, H. Murakawa, Numerical simulation of temperature field and residual stress in multi- 429 pass welds in stainless steel pipe and comparison with experimental measurements, Comput. 430 Mater. Sci. 37 (2006) 269-277, http://dx.doi.org/10.1016/j.commatsci.2005.07.007. 431

[25] L. Lutterotti, S. Matthies, H.-R. Wenk, A.S. Schultz, J.W. Richardson, Combined texture and 432 structure analysis of deformed limestone from time-of-flight neutron diffraction spectra, J. 433 Appl. Phys. 81 (1997) 594, http://dx.doi.org/10.1063/1.364220.

[26] H.-R. Wenk, L. Lutterotti, P. Kaercher, W. Kanitpanyacharoen, L. Miyagi, R. Vasin, Rietveld 435 texture analysis from synchrotron diffraction images. II. Complex multiphase materials 436 and diamond anvil cell experiments, Powder Diffract. 4 (2014) 1-13, http://dx.doi.org/ 437 10.1017/S0885715614000360.

[27] P. Šittner, L. Heller, J. Pilch, C. Curfs, T. Alonso, D. Favier, Young's modulus of austenite and 439 martensite phases in superelastic NiTi wires, J. Mater. Eng. Perform. 23 (2014) 2303-2314, 440 http://dx.doi.org/10.1007/s11665-014-0976-x.

[28] R. Boyer, G. Welsch, E. Collings, Materials Properties Handbook: Titanium Alloys, first ed. 442 Ohio, ASM International, 1994.

[29] A.M. Korsunsky, S.P. Collins, R. Alexander Owen, M.R. Daymond, S. Achtioui, K.E. James, 444 Fast residual stress mapping using energy-dispersive synchrotron X-ray diffraction on sta- 445 tion 16.3 at the SRS, J. Synchrotron Radiat. 9 (2002) 77-81, http://dx.doi.org/10.1107/ 446 S0909049502001905.

[30] A.P. Hammersley, S.O. Svensson, M. Hanfland, A.N. Fitch, D. Hausermann, Two- 448 dimensional detector software: from real detector to idealised image or two-theta scan, 449 High Pressure Res. 14 (1996) 235-248, http://dx.doi.org/10.1080/08957959608201408. 450

[31] G.A. Moraitis, G.N. Labeas, Prediction of residual stresses and distortions due to laser beam 451 welding of butt joints in pressure vessels, Int. J. Press. Vessel. Pip. 86 (2009) 133-142, 452 http://dx.doi.org/10.1016/j.ijpvp.2008.11.004.

32] J.C.M. Li, Microstructure and properties of materials, World Scientific, first ed, 1996, http:// 454 dx.doi.org/10.1142/2882

[33] A.R. Pelton, J. Dicello, S. Miyazaki, Optimisation of processing and properties of medical 456 grade Nitinol wire, Minim. Invasive Ther. Allied Technol. 9 (2000) 107-118, http://dx. 457 doi.org/10.3109/13645700009063057. 
[34] D. Akbari, I. Sattari-Far, Effect of the welding heat input on residual stresses in butt-welds of dissimilar pipe joints, Int. J. Press. Vessel. Pip. 86 (2009) 769-776, http://dx.doi.org/10. 1016/j.ijpvp.2009.07.005.

[35] X. Song, M. Xie, F. Hofmann, T.S. Jun, T. Connolley, C. Reinhard, et al., Residual stresses in linear friction welding of aluminium alloys, Mater. Des. 50 (2013) 360-369, http://dx. doi.org/10.1016/j.matdes.2013.03.051.
[36] L.A. Vieira, F.M.B. Fernandes, R.M. Miranda, R.J.C. Silva, L. Quintino, A. Cuesta, et al., Me- 465 chanical behaviour of Nd:YAG laser welded superelastic NiTi, Mater. Sci. Eng. A 528466 (2011) 5560-5565, http://dx.doi.org/10.1016/j.msea.2011.03.089

[37] J.P. Oliveira, Z. Zeng, T. Omori, N. Zhou, R.M. Miranda, F.M.B. Fernandes, Improvement of 468 damping properties in laser processed superelastic Cu-Al-Mn shape memory alloys, 469 Mater. Des. 98 (2016) 280-284, http://dx.doi.org/10.1016/j.matdes.2016.03.032 